\title{
Authorship Correction: Factors Associated With Willingness to Use Pre-Exposure Prophylaxis in Brazil, Mexico, and Peru: Web-Based Survey Among Men Who Have Sex With Men
}

Thiago Silva Torres ${ }^{1 *}, \mathrm{PhD}$; Kelika A Konda ${ }^{2 *}, \mathrm{PhD}$; E Hamid Vega-Ramirez ${ }^{3,4^{*}}, \mathrm{MD}, \mathrm{MSc}$; Oliver A Elorreaga ${ }^{2}$, MSc; Dulce Diaz-Sosa ${ }^{3,4}$, PsyD; Brenda Hoagland ${ }^{1}$, MD, PhD; Steven Diaz ${ }^{5}$, MD; Cristina Pimenta ${ }^{6}$, PhD; Marcos Benedetti ${ }^{1}$, MSc; Hugo Lopez-Gatell ${ }^{7}, \mathrm{PhD}$; Rebeca Robles-Garcia ${ }^{4}, \mathrm{PhD}$; Beatriz Grinsztejn ${ }^{1}, \mathrm{MD}, \mathrm{PhD}$; Carlos Caceres $^{2}, \mathrm{MD}, \mathrm{PhD}$; Valdilea G Veloso ${ }^{1}, \mathrm{MD}, \mathrm{PhD}$; ImPrEP Study Group ${ }^{1,2,3}$

${ }^{1}$ Instituto Nacional de Infectologia Evandro Chagas, Fundação Oswaldo Cruz (INI/Fiocruz), Rio de Janeiro, Brazil

${ }^{2}$ Centro de Investigación Interdisciplinaria en Sexualidad Sida y Sociedad, UPCH, Lima, Peru

${ }^{3}$ Condesa \& Condesa-Iztapalapa Specialized Clinics, Mexico City, Mexico

${ }^{4}$ National Institute of Psychiatry Ramon de la Fuente Muñiz, Mexico City, Mexico

${ }^{5}$ Center for Prevention and Comprehensive Healthcare for HIV/AIDS of Mexico City, Mexico City, Mexico

${ }^{6}$ Brazilian Ministry of Health, Brasília, Brazil

${ }^{7}$ National Institute of Public Health, Mexico City, Mexico

*these authors contributed equally

\section{Corresponding Author:}

Thiago Silva Torres, $\mathrm{PhD}$

Instituto Nacional de Infectologia Evandro Chagas, Fundação Oswaldo Cruz (INI/Fiocruz)

Av Brasil 4365 Manguinhos

Rio de Janeiro, 21040-900

Brazil

Phone: 5538659623

Fax: 5538659679

Email: thiago.torres@ini.fiocruz.br

\section{Related Article:}

Correction of: http://publichealth.jmir.org/2019/2/e13771/

(JMIR Public Health Surveill 2019;5(3):e15504) doi: 10.2196/15504

In "Factors Associated With Willingness to Use Pre-Exposure Prophylaxis in Brazil, Mexico, and Peru: Web-Based Survey Among Men Who Have Sex With Men" (JMIR Public Health Surveill 2019;5(2):e13771), the metadata information for author Cristina Pimenta (listed in 8th position) was accidentally overwritten by a duplicate of author Marcos Benedetti (listed in 9th position) when attempting to correct the spelling of Marcos' surname.

Authorship was previously as follows:

\section{Thiago Silva Torres, Kelika A Konda, E Hamid Vega-Ramirez, Oliver A Elorreaga, Dulce Diaz-Sosa, Brenda Hoagland, Steven Diaz, Marcos Benedetti, Marcos Bennedeti, Hugo Lopez-Gatell, Rebeca Robles-Garcia, Beatriz Grinsztejn, Carlos Caceres, Valdilea G Veloso, ImPrEP Study Group}

The duplicate name and associated information for the author in 8 th position has been adjusted to list Cristina Pimenta, $\mathrm{PhD}$, with affiliation "Brazilian Ministry of Health, Brasília, Brazil", and the spelling of "Bennedeti" for the author in 9th position has been corrected to "Benedetti". Updated authorship is now as follows:

\section{Thiago Silva Torres, Kelika A Konda, E Hamid Vega-Ramirez, Oliver A Elorreaga, Dulce Diaz-Sosa, Brenda Hoagland, Steven Diaz, Cristina Pimenta, Marcos Benedetti, Hugo Lopez-Gatell, Rebeca Robles-Garcia, Beatriz Grinsztejn, Carlos Caceres, Valdilea G Veloso, ImPrEP Study Group}

The correction will appear in the online version of the paper on the JMIR website on July 18, 2019, together with the publication of this correction notice. Because this was made after submission to PubMed, PubMed Central, and other full-text repositories, the corrected article also has been resubmitted to those repositories. 
This is a non-peer-reviewed article. Submitted 15.07.19; accepted 15.07.19; published 18.07.19.

Please cite as:

Torres TS, Konda KA, Vega-Ramirez EH, Elorreaga OA, Diaz-Sosa D, Hoagland B, Diaz, S, Pimenta C, Benedetti M, Lopez-Gatell H, Robles-Garcia R, Grinsztejn B, Caceres C, Veloso VG, ImPrEP Study Group

Authorship Correction: Factors Associated With Willingness to Use Pre-Exposure Prophylaxis in Brazil, Mexico, and Peru: Web-Based Survey Among Men Who Have Sex With Men

JMIR Public Health Surveill 2019;5(3):e15504

URL: http://publichealth.jmir.org/2019/3/e15504/

doi: $10.2196 / 15504$

PMID: $\underline{31322130}$

(C)Thiago Silva Torres, Kelika A Konda, E Hamid Vega-Ramirez, Oliver A Elorreaga, Dulce Diaz-Sosa, Brenda Hoagland, Steven Diaz, Cristina Pimenta, Marcos Benedetti, Hugo Lopez-Gatell, Rebeca Robles-Garcia, Beatriz Grinsztejn, Carlos Caceres, Valdilea G Veloso, ImPrEP Study Group. Originally published in JMIR Public Health and Surveillance (http://publichealth.jmir.org), 18.07.2019. This is an open-access article distributed under the terms of the Creative Commons Attribution License (https://creativecommons.org/licenses/by/4.0/), which permits unrestricted use, distribution, and reproduction in any medium, provided the original work, first published in JMIR Public Health and Surveillance, is properly cited. The complete bibliographic information, a link to the original publication on http://publichealth.jmir.org, as well as this copyright and license information must be included. 